\title{
Inhibition of nuclear factor of activated $T$ cells (NFAT) c3 activation attenuates acute lung injury and pulmonary edema in murine models of sepsis
}

\author{
Manjula Karpurapu ${ }^{1}$, Yong Gyu Lee ${ }^{1}$, Ziqing Qian², Jin Wen², Megan N. Ballinger ${ }^{1}$, \\ Luiza Rusu ${ }^{1}$, Sangwoon Chung ${ }^{1}$, Jing Deng ${ }^{1}$, Feng Qian ${ }^{1}$, Brenda F. Reader ${ }^{1}$, Teja \\ Srinivas Nirujogi ${ }^{1}$, Gye Young Park ${ }^{3}$, Dehua Pei ${ }^{2}$ and John W. Christman ${ }^{1}$ \\ ${ }^{1}$ Pulmonary, Allergy, Critical Care and Sleep Medicine, Ohio State University Wexner Medical Center, Davis Heart and Lung \\ Research Institute, Columbus, $\mathrm{OH} 43210$, USA \\ ${ }^{2}$ Department of Chemistry and Biochemistry, The Ohio State University, Columbus, OH 43210, USA \\ ${ }^{3}$ Pulmonary, Allergy, Critical Care and Sleep Medicine, University of Illinois, Chicago, IL 60612, USA \\ Correspondence to: John W. Christman, email: John.Christman@osumc.edu \\ Manjula Karpurapu, email: Manjula.Karpurapu@osumc.edu
}

Keywords: macrophage; NFAT's; acute lung injury; pulmonary edema; CP9-ZIZIT

Received: September 27, $2016 \quad$ Accepted: December 22, $2017 \quad$ Published: January 25, 2018

Copyright: Karpurapu et al. This is an open-access article distributed under the terms of the Creative Commons Attribution License 3.0 (CC BY 3.0), which permits unrestricted use, distribution, and reproduction in any medium, provided the original author and source are credited.

\section{ABSTRACT}

Specific therapies targeting cellular and molecular events of sepsis induced Acute Lung Injury (ALI) pathogenesis are lacking. We have reported a pivotal role for Nuclear Factors of Activated T cells (NFATc3) in regulating macrophage phenotype during sepsis induced ALI and subsequent studies demonstrate that NFATc3 transcriptionally regulates macrophage CCR2 and TNFa gene expression. Mouse pulmonary microvascular endothelial cell monolayer maintained a tighter barrier function when co-cultured with LPS stimulated NFATc3 deficient macrophages whereas wild type macrophages caused leaky monolayer barrier. More importantly, NFATC3 deficient mice showed decreased neutrophilic lung inflammation, improved alveolar capillary barrier function, arterial oxygen saturation and survival benefit in lethal CLP sepsis mouse models. In addition, survival of wild type mice subjected to the lethal CLP sepsis was not improved with broad-spectrum antibiotics, whereas the survival of NFATc3 deficient mice was improved to $40-60 \%$ when treated with imipenem. Passive adoptive transfer of NFATc3 deficient macrophages conferred protection against LPS induced ALI in wild type mice. Furthermore, CP9-ZIZIT, a highly potent, cell-permeable peptide inhibitor of Calcineurin inhibited NFATc3 activation. CP9-ZIZIT effectively reduced sepsis induced inflammatory cytokines and pulmonary edema in mice. Thus, this study demonstrates that inhibition of NFATc3 activation by CP9-ZIZIT provides a potential therapeutic option for attenuating sepsis induced ALI/pulmonary edema.

\section{INTRODUCTION}

Alveolar macrophages are key innate immune cells that orchestrate the lung immune response. Studies from our laboratory and others have shown that administration of clodronate liposomes, which induced depletion of macrophages, suppressed endotoxin-induced neutrophilic inflammation in mouse lungs [1-3]. We have also shown that mice whose macrophages are PU.1-deficient, and thus functionally incompetent, have decreased lung inflammation and pulmonary edema in the setting of severe sepsis indicating a central role of macrophages in pulmonary inflammation and edema development [4]. However, it is unknown whether and how macrophages directly influence lung vascular permeability function that results in pulmonary edema. Our previous studies have 
identified critical protein factors in macrophages that play a role in initiation, mediation, and resolution of acute lung injury $[4,5]$. We have examined the gene targets of sepsis in macrophages and discovered that NFATc3 is activated during sepsis and regulates expression of induced Nitric Oxide Synthase [6]. Our current studies indicated that NFATc3 also regulates CCR2, TNF $\alpha$ and few other inflammatory genes in macrophages upon LPS stimulation. Initially, NFATs were reported to regulate T-cell development, activation and differentially affect cellular function in cancer $[7,8]$. NFATc3 activation and its functional significance in sepsis-induced ALI have not been examined in macrophages that are critical innate immune cells involved in ALI pathogenesis.

The first member of NFAT family, NFATc2 was discovered in T-cells as an inducible nuclear factor that binds to the antigen receptor response element-2 of the interleukin-2 promoter in human T cells $[9,10]$. Subsequently, it was found that NFATs are not expressed exclusively in $\mathrm{T}$ cells, but are ubiquitously expressed in various immune and non-immune cells in the vertebrate systems [11-18]. NFATs are critical regulators of developmental control functions including cell fate determination, embryonic development, and organogenesis of the cardiac, hematopoietic, skeletal, and neuronal systems [19-22]. The NFAT protein family consists of five members referred as NFAT1 (NFATc2 or NFATp), NFAT2 (NFATc1 or NFATc), NFAT3 (NFATc4), NFAT4 (NFATc3 or NFATx), and NFAT5 (tonicity-responsive enhancer-binding protein (TonEBP) [23]. NFAT1, NFAT2, NFAT3 and NFAT4 are activated by cellular calcium influx and NFAT5 is activated by osmotic stress. The calciumresponsive NFAT isoforms (NFAT1-NFAT4) exist in hyper-phosphorylated states within the cytoplasm and are activated by increased intracellular calcium levels via dephosphorylation by calcineurin and nuclear translocation [24]. NFATs that translocate to the nucleus activate transcription of downstream target genes, thus directly linking calcium signaling to gene expression. To date, only calcineurin is known to activate the NFAT1-4 transcription factors thereby controlling the expression of a broad range of genes. NFAT proteins were implicated in pathogenesis of various inflammatory pathologies. Research to identify NFAT inhibitors is underway since their discovery but yielded little success $[25,26]$.

Aramburu et al., have discovered a 14mer VIVIT peptide with higher specificity that inhibits NFAT calcineurin interaction thereby inhibiting dephosphorylation/ nuclear translocation of NFAT1-4 [27]. VIVIT has a modest binding affinity for calcineurin $\left(K_{\mathrm{D}}=500 \mathrm{nM}\right)$. To improve its potency, the two valine residues in VIVIT were replaced with tert-leucine and the resulting peptide, ZIZIT, is an order of magnitude more potent $\left(K_{\mathrm{D}}=43 \mathrm{nM}\right)$ [28]. In this work, we covalently attached ZIZIT to a cyclic cell-penetrating peptide to generate a highly potent and cell-permeable calcineurin inhibitor, CP9-ZIZIT [29, 30].
Compared to VIVIT, CP9-ZIZIT is expected to possess higher affinity for calcineurin, better cell permeability, and improved stability against proteolysis which would predict higher efficacy in inactivating NFATs [28, 30].

Knockout mice of each NFAT family member exhibit distinct phenotypic defects, possibly due to the cell type-specific regulation and expression profiles of each NFAT. However, in vivo, the contribution of NFATs to the macrophage-mediated pulmonary innate immune system response during sepsis-induced ALI has not been addressed. In our earlier studies, we reported that LPS activated NFATc3 regulates macrophage-specific iNOS, which is critical for macrophage bactericidal activity and their role in host defense [6]. In the current manuscript, we have identified a novel role for NFATc3 in the regulation of inflammatory genes produced by macrophages during murine sepsis-induced ALI, and inhibiting NFATc3 activation with the high affinity CP9-ZIZIT peptide notably attenuated pulmonary edema and lung wet to dry weight ratios during LPS inhalation-induced ALI in mice.

\section{RESULTS}

\section{LPS activates NFATc3 selectively in macrophages and NFATC3 is a transcriptional regulator of inflammatory genes}

We observed that in vitro treatment with LPS, an inducer of sepsis-like pathophysiology in mice, results in induction of NFATc3 activation in macrophages. Cytoplasmic and nuclear proteins from LPS-stimulated total lung macrophages were immuno-blotted with antibodies specific to NFAT1-NFAT4. LPS induced a highly specific, time-dependent translocation of NFATc3 from the cytoplasm to the nuclear compartment (Figure 1A). NFATc1 and NFATc4 are constitutively present in the cytoplasm and nucleus, respectively. NFATc2 was present predominantly in cytoplasm indicating that only NFATc3, among the tested NFATs, undergoes activation/nuclear translocation in response to LPS treatment in lung macrophages. Although, NFATc3 is abundantly expressed in mouse alveolar epithelial type II cells (AEC Type II), LPS stimulation does not result in NFATc3 translocation from cytoplasm to nucleus similar to pulmonary microvascular endothelial cells (PMVECs) (Figure 1B-1C). Thus, compared to pulmonary microvascular endothelium and alveolar type II epithelium, NFATc3 alone is activated by LPS in lung macrophages (Figure 1A-1C).

Since NFATc3 is selectively activated in lung macrophages by LPS, we next aimed to determine the role of activated NFATc 3 on bone marrow derived macrophage (BMDM) inflammatory gene expression by using a PCR array for mouse inflammatory and autoimmunity genes (SABioscience, PAMM-077A). WT macrophages, stimulated with LPS showed distinct upregulation of 
inflammatory genes such as TNF $\alpha$, iNOS, CCR2, and CCL2 (Supplementary Table 1). Comparison of LPS stimulated NFATc $3^{--}$and WT BMDM gene expression indicated distinct down regulation of LPS induced CCR2 and $\mathrm{TNF} \alpha$ in $\mathrm{NFATc}^{-/-}$macrophages (Figure $2 \mathrm{~A}-2 \mathrm{~B}$ ), suggesting that NFATc 3 regulates macrophage gene expression thereby regulates pathogenesis of sepsis induced-ALI. To test this hypothesis, we characterized NFATc3 deficient and WT macrophages and measured the outcomes of sepsis-induced ALI in NFATc $3^{--}$and WT mice. Next, we determined if NFATc3 transcriptionally regulates CCR2 and TNF $\alpha$ by binding to their promoters. LPS increased NFATc3 binding to NFAT consensus sequence in CCR2 and TNF $\alpha$ and promoters in WT BMDM whereas there was no such increase in NFATc $3^{-1-}$ BMDM (Figure 2C-2D). In addition, TNF $\alpha$ released into the media after LPS stimulation in NFATc $3^{-1-}$ BMDMs was restored to levels comparable with those of WT BMDMs, when NFATc $3^{-/}$cells were electroporated with NFATc3 expressing plasmid and stimulated with LPS (Figure 2E). NFATc3 overexpression in NFATc $3^{-/}$BMDMs confirmed the functional role of NFATc3 in regulation of $\mathrm{TNF} \alpha$.

\section{NFATc $^{--}$macrophages modulate PMVEC monolayer barrier function}

$\mathrm{NFATc}^{-1-}$ macrophages distinctly express decreased inflammatory molecules indicating a potential link between NFATc3-deficient macrophages and integrity of surrounding microvascular monolayer barrier properties. Therefore, we determined whether NFATc3 deficiency in macrophages would affect the mouse PMVEC monolayer barrier function. To test this, we co-cultured macrophages with PMVECs and determined the PMVEC monolayer barrier function. Hanging transwell cell culture inserts were seeded to $100 \%$ confluence with mouse PMVEC isolated by CD31 Miltenyi magnetic beads and further co-cultured with NFATc $^{-/-}$or WT BMDMs that were grown in 24 well plates stimulated with LPS for $8 \mathrm{hrs}$. At the time of initiation of co-culture, FITC-Dextran (10 kDa) was added to PMVEC monolayer grown cell culture inserts and flux of FITCDextran across the monolayer was measured after $24 \mathrm{~h}$. PMVEC cell culture inserts placed on control BMDMs (PBS) showed no detectable levels of FITC-dextran in the bottom wells indicating maintenance of tighter PMVEC monolayer barrier function whereas inserts placed into wells with LPS treated WT BMDMs showed increased accumulation of FITC-dextran in bottom wells (Figure 3A). Interestingly, PMVEC co-cultured with LPS stimulated NFATc $^{-1-}$ BMDMs showed decreased FITC-dextran flux across the monolayer compared to WT BMDM (Figure 3A). Homogeneity of NFATc $3^{-/}$BMDMs was confirmed by staining for the macrophage marker F4/80 (Ab F4/80-PE) and NFATc3 (anti-NFATc3-APC-Figure 3C), and PMVECs were confirmed by CD31-PE staining (Figure 3D). Effect of NFATc3 driven macrophage TNF $\alpha$ expression on PMVEC monolayer permeability was determined using neutralizing TNF $\alpha$ antibody in co-cultures. Pretreatment of WT-BMDM
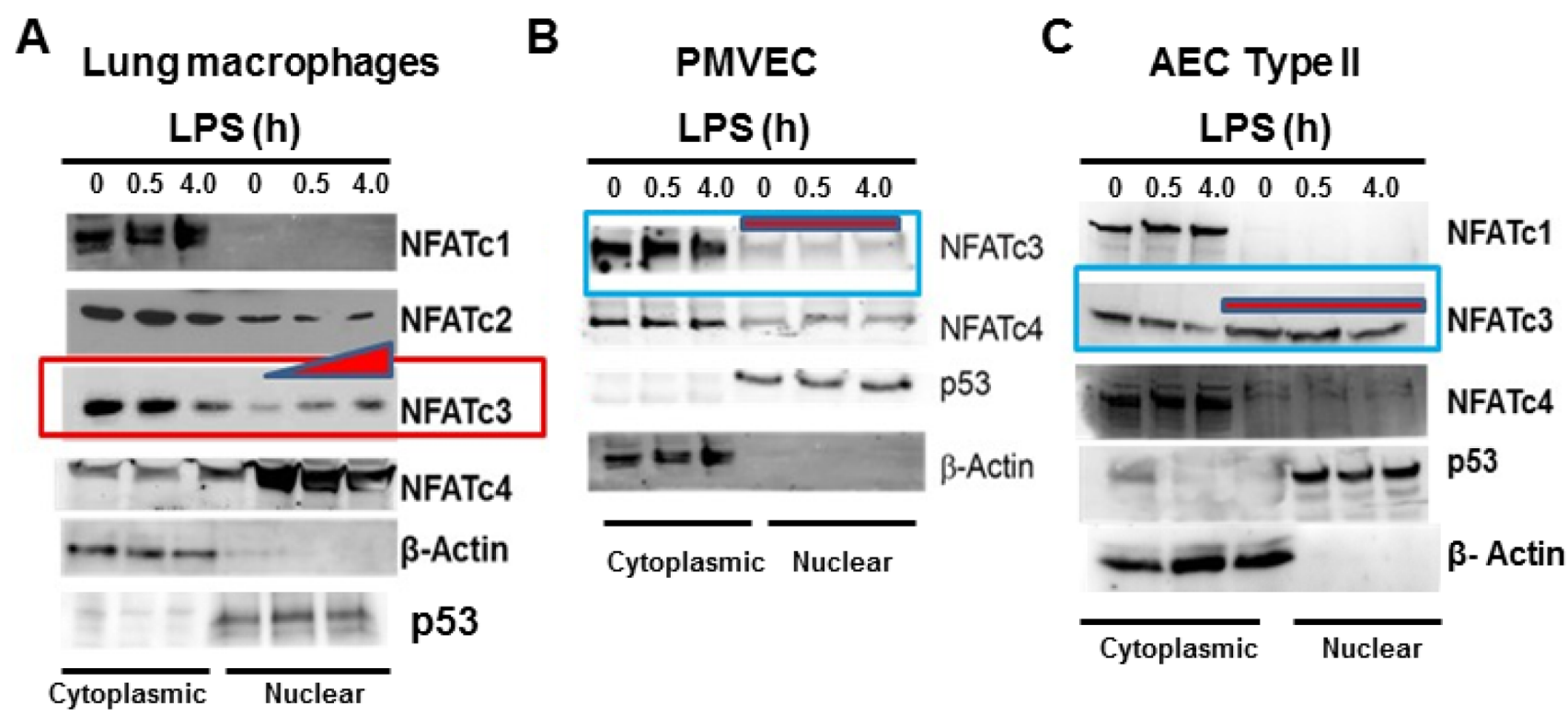

Figure 1: LPS induced NFATc3 activation and translocation is macrophage specific. (A) Mouse total lung macrophages were stimulated with LPS (100 ng/mL for 0.5 and $4.0 \mathrm{~h})$. The cytoplasmic and nuclear proteins were isolated using Peirce Nuclear and Cytoplasmic protein isolation kit and equal amount of proteins were immunoblotted for NFATc1, NFATc2, NFATc3 and NFATc4 to determine their cytoplasmic vs. nuclear distribution. (B) Mouse PMVEC were treated with LPS (100 ng/mL for 0.5 and $4.0 \mathrm{~h})$. The cytoplasmic and nuclear proteins were isolated and analyzed for NFAT1-NFAT4 nuclear translocation. (C) Mouse AEC type II cells were treated with LPS (100 ng/mL for 0.5 and $4.0 \mathrm{~h}$ ) and analyzed for NFAT1-NFAT4 nuclear translocation. Purity of cytoplasmic and nuclear proteins is determined by immunoblotting with $\beta$-Actin and $\mathrm{p} 53$. 
with neutralizing TNF $\alpha$ antibody significantly decreased FITC-dextran flux, indicating reduced permeability of mouse PMVEC monolayer (Figure 3B). These data established a strong correlation between macrophage NFATc3 dependent TNF $\alpha$ expression and pulmonary microvascular endothelial cell barrier function.

\section{$\mathrm{NFATc}^{-/-}$mice compared to WT mice show healthy lung parameters during sepsis-induced ALI}

Since macrophages with altered expression levels of $\mathrm{TNF} \alpha, \mathrm{CCR} 2$ and iNOS are expected to affect lung inflammation, homeostasis and host resistance, we determined the functional implication of NFATc3 deletion on sepsis-induced ALI in mouse CLP sepsis models. We subjected $\mathrm{NFATc}^{-/-}$and WT littermates to moderate CLP or sham surgery. At 24 hours, the degree of pulmonary edema and the intensity of inflammation were assessed by measuring protein and $\mathrm{TNF} \alpha$ levels in broncho alveolar lavage fluid (BALF) (Figure 4A-4B). WT mice subjected to moderate CLP showed greater protein leakage, TNF $\alpha$ expression, and neutrophil numbers in BALF compared to NFATc $^{-/}$mice (Figure 4A-4D). These data suggested that NFATc3-deficient mice are protected from ALI associated pulmonary edema during polymicrobial abdominal sepsis. However, in our previous study, NFATc $3^{-1}$ polymicrobial septic mice have been found to have increased bacterial colony forming units (CFUs) per gram of lung tissue [6]. It is interesting to note that in our study the neutrophilic infiltration in $\mathrm{NFATc}^{-/-}$mouse lung was marginally reduced to only about $45 \%$ of WT, which is apparently a level of neutrophilic lung inflammation that is adequate for bacterial phagocytosis but may not be sufficient to
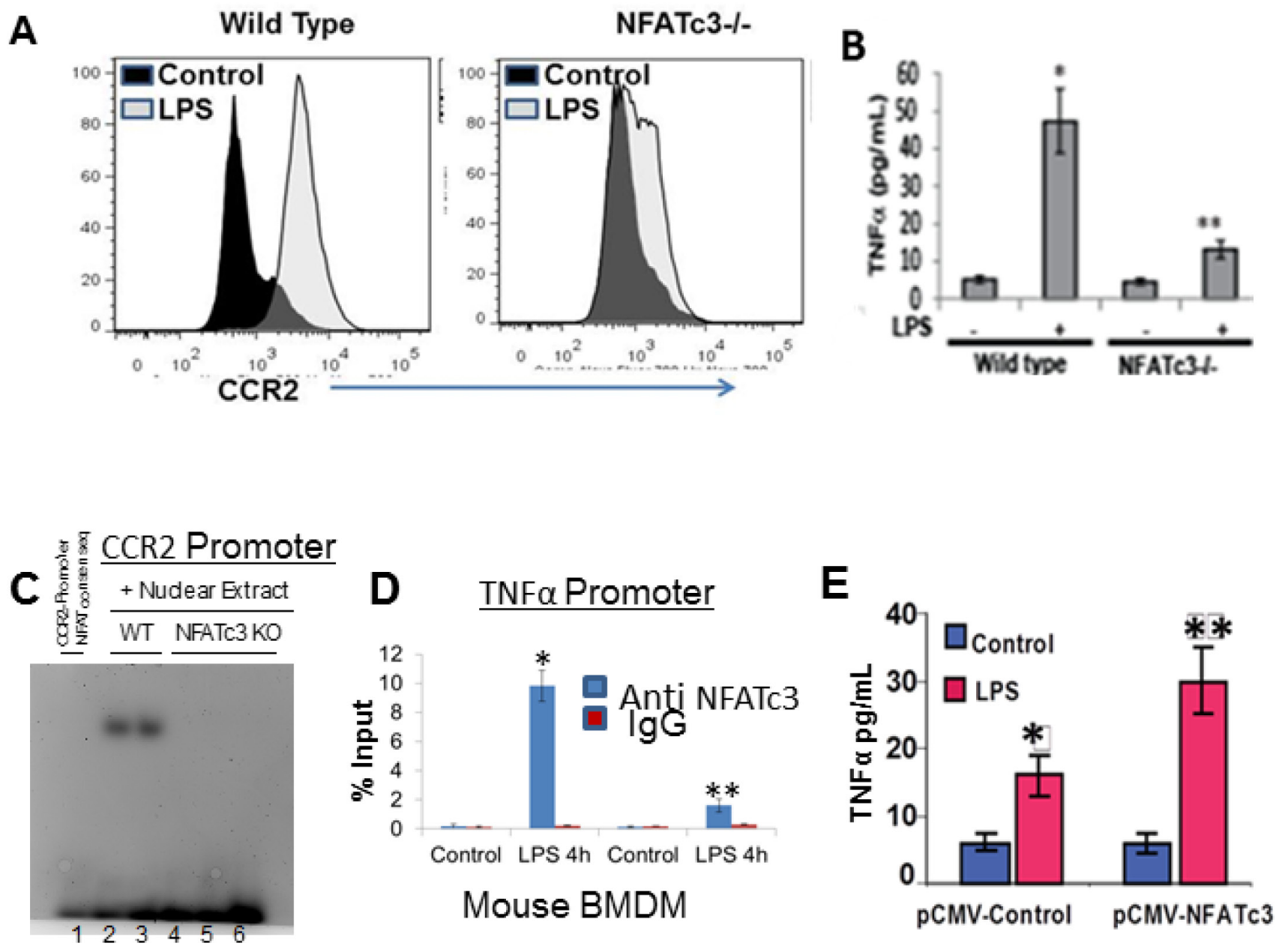

Figure 2: NFATc3 transcriptionally regulates CCR2 and TNF $\alpha$ expression. BMDMs from WT and NFATc $3^{-/-}$mice were stimulated with LPS for $24 \mathrm{~h}$ and analyzed for (A). Expression of CCR2 by flow cytometry (B) Extracellular medium for TNF $\alpha$ release by ELISA. (C) Binding of NAFTc3 to the CCR2 promoter was determined by Electrophoretic mobility shift assay. (D) Binding of NAFTc3 to the TNF $\alpha$ promoter was determined by Chromatin ImmunoPrecipitation using QIAGEN One day ChIP kit. (E) NFATc3 was overexpressed in NFATc $3^{-/-}$BMDMs by electroporation with a pCMV-NFATc3 plasmid and stimulated with LPS for $24 \mathrm{~h}$. LPS induced TNF $\alpha$ release in to the culture medium was measured using R\&D systems Quantikine TNF $\alpha$ ELISA kit. B-D-E, ${ }^{*} P \leq 0.01$ LPS vs. control; ${ }^{* *} p \leq 0.001$ $\mathrm{NFATc}^{---}$vs. WT or pCMV-NFATc3 vs pCMV-Control. 
cause permeability pulmonary edema (Figure 4C-4D). Furthermore, the macrophage numbers in BALF were also significantly reduced in NFATc $3^{-/-}$mice (Figure 4C-4D). Similarly, NFATc $3^{--}$mice when challenged with LPS (15 $\mathrm{mg} / \mathrm{kg}$ i.p) showed decreased neutrophilic inflammation and intact alveolar architecture compared to wild type mice (Figure 4E). Next, we measured the pulmonary arterial oxygenation using MouseOx Pulse Oximeter (STARR Life Sciences Corp). As shown in Figure 5A, NFATc $3^{-1-}$ mice maintained $9-12 \%$ increased arterial oxygenation at 8 $\mathrm{h}$ and $24 \mathrm{~h}$ post LPS (15 mg/kg i.p.) injection compared to WT mice. Our earlier studies supported NFATc3 activation induced iNOS expression to be necessary for maintaining antibacterial pulmonary host defense [6] whereas current results show that NFATc3 activation mediates alveolar capillary barrier dysfunction (Figures $3 \mathrm{~A}, 4 \mathrm{~A}, 5 \mathrm{~A})$. This raises concerns regarding the relative benefit of protecting alveolar capillary barrier function at the expense of a detrimental impact on antibacterial host defense by targeting NFATc3 activation. To address this important clinical concern, we investigated whether the increase in bacterial infection observed in NFATc $3^{-1}$ mice translated into a poorer prognosis of CLP-induced mortality or whether the improved arterial oxygenation and decreased pulmonary vascular leakage or edema more than compensated, leading to a better outcome. NFATc $3^{-/}$ and WT mice were subjected to severe sepsis by using a lethal model of CLP and were monitored for survival over $96 \mathrm{~h}$. Compared to WT the NFATc $3^{-/-}$mice showed a $20 \%$ improvement in survival rate at $96 \mathrm{~h}$ whereas, WT-CLP mice showed 100\% lethality by 72 hours (Figure 5B). Furthermore, $60 \%$ of NFATc3-deficient mice survived with the administration of the broad-spectrum antibiotic imipenem (Figure 5C). In contrast, the lethality of the WT severe CLP mice was not improved any further by Imipenem (Figure 5C). These data, all together, indicate that $\mathrm{NFATc}^{--}$mice show decreased pulmonary protein leakage, neutrophilic infiltration, improved arterial oxygenation and survival despite the excessive bacterial load detected in lung tissue in our previous study [6]. Despite the compromised host defense in NFATC $3^{-/}$mice, management with broad spectrum antibiotics improved the overall lung function during sepsis induced ALI and survival. To determine if the decreased pulmonary edema in $\mathrm{NFATc}^{-/-}$mice is due to
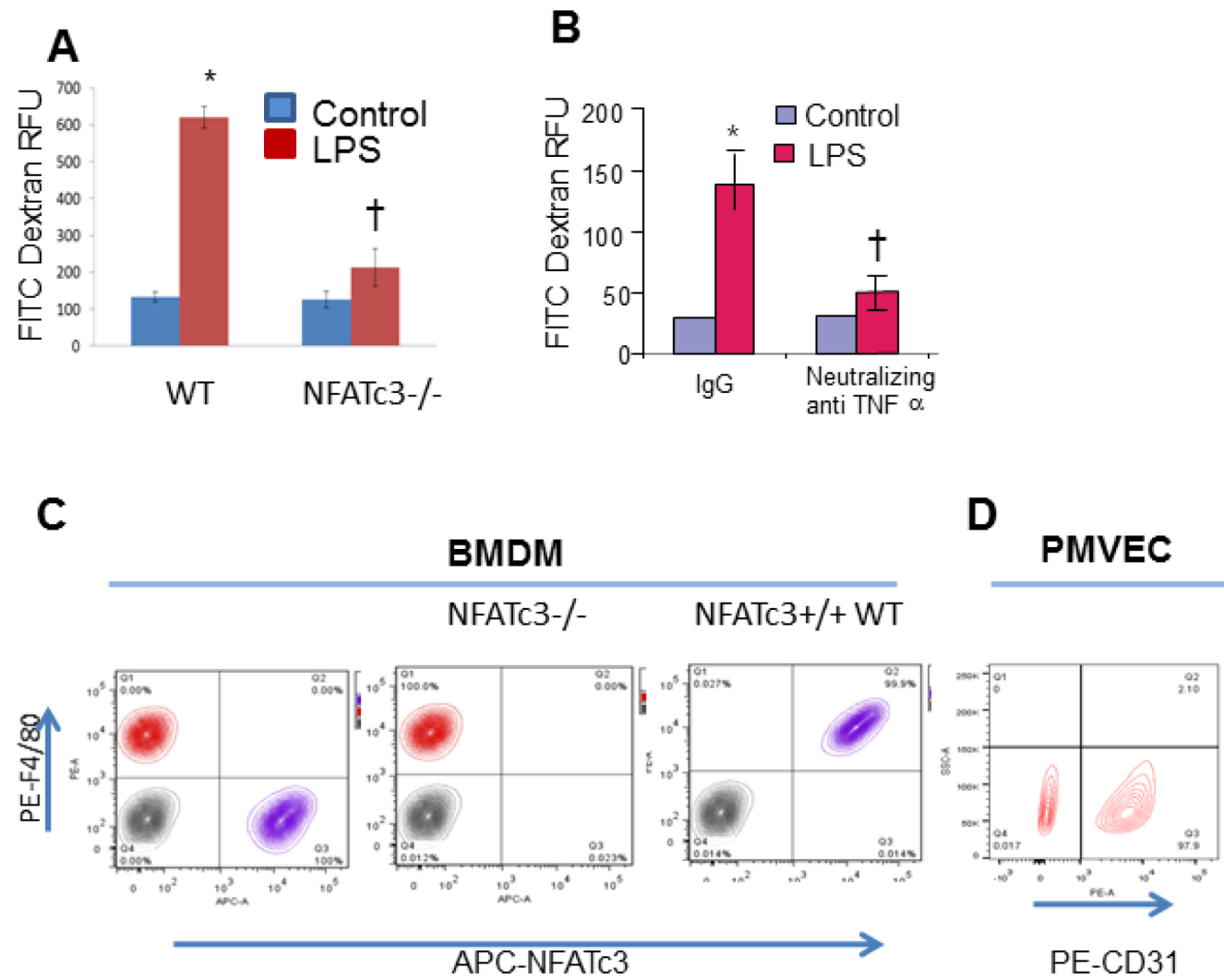

Figure 3: NFATc3 $^{-/}$macrophages positively modulate mouse PMVEC permeability. Mouse BMDM stimulated with LPS $(100 \mathrm{ng} / \mathrm{mL})$ for $24 \mathrm{~h}$ were co-cultured with mouse PMVEC monolayer grown on cell culture inserts, added with FITC-Dextran to the trans wells at the time of initiating co-culture. (A) Flux of FITC-Dextran in WT and NFATc $3^{--}$macrophage co-culture was determined by measuring fluorescence of the medium in the bottom wells as described in methods. Similarly, (B) FITC-Dextran flux in neutralizing TNF $\alpha$ pre- treated WT BMDM cells is quantitated as described in methods. (C) Homogeneity of NFATc $3^{--}$\& WT BMDM was determined by staining with anti-APC-NFATc3 and F480. (D) Homogeneity of PMVEC is confirmed by staining with anti-PE-CD31. A-B ${ }^{*} p \leq 0.001$ LPS vs PBS; ${ }^{\dagger} p \leq 0.01 \mathrm{NFATc}^{-/-} / \mathrm{NeutralizingTNF} \alpha$ vs NFATc ${ }^{+/+}(\mathrm{WT}) /$ Normal IgG. 
macrophage mediated phenotype, WT and $\mathrm{NFATc}^{-/}$mice are depleted of lung macrophages by clodronate liposomes for $72 \mathrm{~h}$ and adoptively transferred with lung macrophages from reciprocal genetic back ground as described earlier [5]. The recipient mice are subjected to LPS or PBS (i.p) challenge. After $24 \mathrm{~h}$, WT mice that received NFATc $3^{--}$lung macrophages and challenged with LPS showed decreased lung wet/dry ratio and BALF protein/TNF $\alpha$ (Figure 6A-
6C). NFATc $3^{-/-}$mice tLPS showed increased lung wet/dry ratio, BALF protein and $\mathrm{TNF} \alpha$ similar to WT mice (Figure 6A-6C). As shown in Figure 6D, Clodronate liposomes depleted resident lung macrophages in recipient mice from $86 \%$ to $34 \%$. Lung tissue homogenates from NFATc $3^{-/}$ mice showed no expression of NFATc 3 and in addition no compensatory expression of NFATc1, NFATc2, and NFATc4 was observed (Supplementary Figure 3).
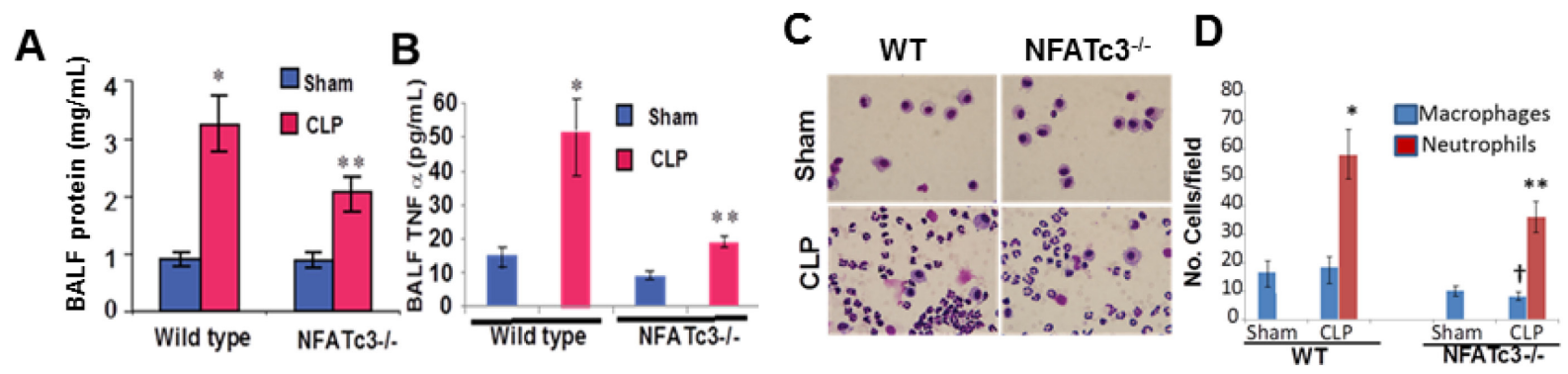

E

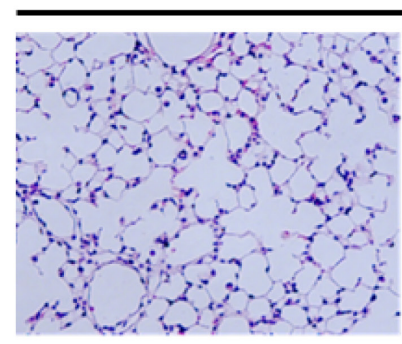

PBS
Wild type

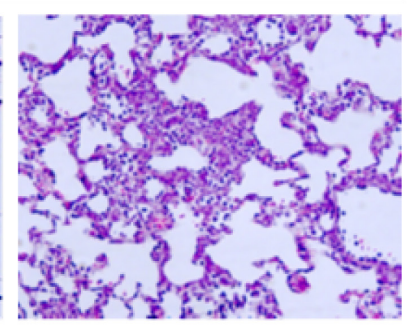

LPS
NFATc3 $^{-1-}$

Figure 4: $\mathrm{NFATc}^{-/-}$mice subjected to abdominal sepsis by CLP show healthy lung parameters. NFATc $3^{-/-}$and WT mice were subjected to CLP or sham surgery and analyzed after $24 \mathrm{~h}$ to determine (A) protein leakage in to BALF, (B). TNF $\alpha$ released in to BALF was measured by ELISA (C-D) Hema 3.0 Stained Neutrophils and macrophages in BALF. (E) NFATc3 $3^{-/}$and WT mice were subjected to LPS (i.p $15 \mathrm{mg} / \mathrm{kg}$ ) sepsis for $16 \mathrm{~h}$. Lungs were fixed, embedded in paraffin, sectioned and H\&E stained. Lung histology showing neutrophilic infiltration in to NFATc $3^{-/-}$and wild type mice. (A-D) ${ }^{*} p \leq 0.001$ WT-CLP vs WT- Sham; ${ }^{* *} p \leq 0.01$ NFATc $3^{-1-}$ CLP vs WT-CLP; ${ }^{\dagger} p \leq 0.05$ macrophages in NFATc $3^{-1-}$ CLP vs WT-CLP.

A

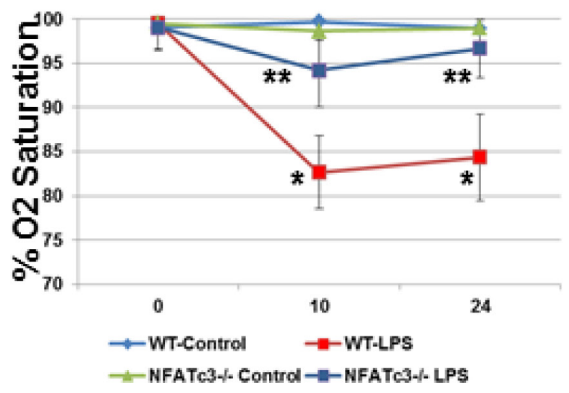

B

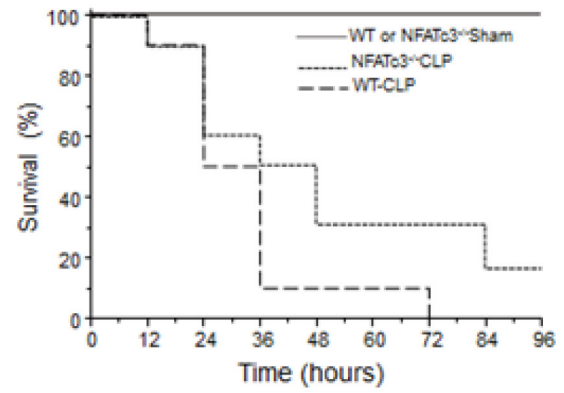

C

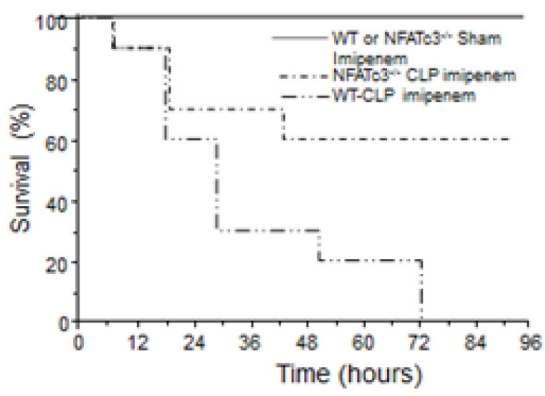

Figure 5: NFATc3 $^{-/}$mice show improved arterial Oxygen saturation and survival compared to wild type mice. (A) NFATc $^{-/-}$and wild type mice $(N=5)$ were injected with $15 \mathrm{mg} / \mathrm{kg}$ LPS i.p and the arterial oxygen saturation was measured using STARR Life Sciences Corp. Pulse Oximeter. (B-C) NFATc $3^{--}$and wild type mice ( $N=5$ sham control group; $N=10$ CLP group) were subjected to severe CLP, maintained on regular or imipenem monohydrate supplemented water and the survival was monitored over a period of

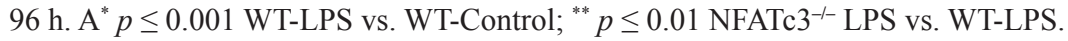




\section{NFATc3-Calcineurin inhibitors offer protective effect against sepsis-induced ALI and pulmonary edema}

To confirm the in vivo results observed in the NFATc3-deficient mice, we next aimed to determine whether pharmacological inhibition of NFAT by a VIVIT expressing plasmid attenuates sepsis-induced ALI. GFP or GFP-VIVIT plasmids were delivered by intra-tracheal injection of plasmid-containing liposomes into WT mice. After $24 \mathrm{~h}$, GFP control and GFP-VIVIT liposome injected mice were subjected to CLP or sham surgery and analyzed after $24 \mathrm{~h}$ for CLP-induced ALI and pulmonary edema.
GFP-VIVIT plasmid transfected mice showed a significant decrease in both EBA extravasation and lung wet to dry ratio compared to GFP-control transfected mice (Figure 7A-7B) indicating that VIVIT expression is associated with improved alveolar endothelial barrier function. To this end, we conjugated a recently developed, highly potent, and proteolytically stable peptide inhibitor against calcineurin, ZIZIT, to a powerful cyclic cell-penetrating peptide $[28,29,30]$. The resulting peptide, CP9-ZIZIT, is a highly potent $\left(K_{\mathrm{D}}=43 \mathrm{nM}\right)$ and cell-permeable calcineurin-NFAT interaction inhibitor. CP9-ZIZIT peptide (Supplementary Figures 1,2) used at much lower concentration $(1 \mu \mathrm{M})$ attenuated TNF $\alpha$ gene expression in LPS stimulated

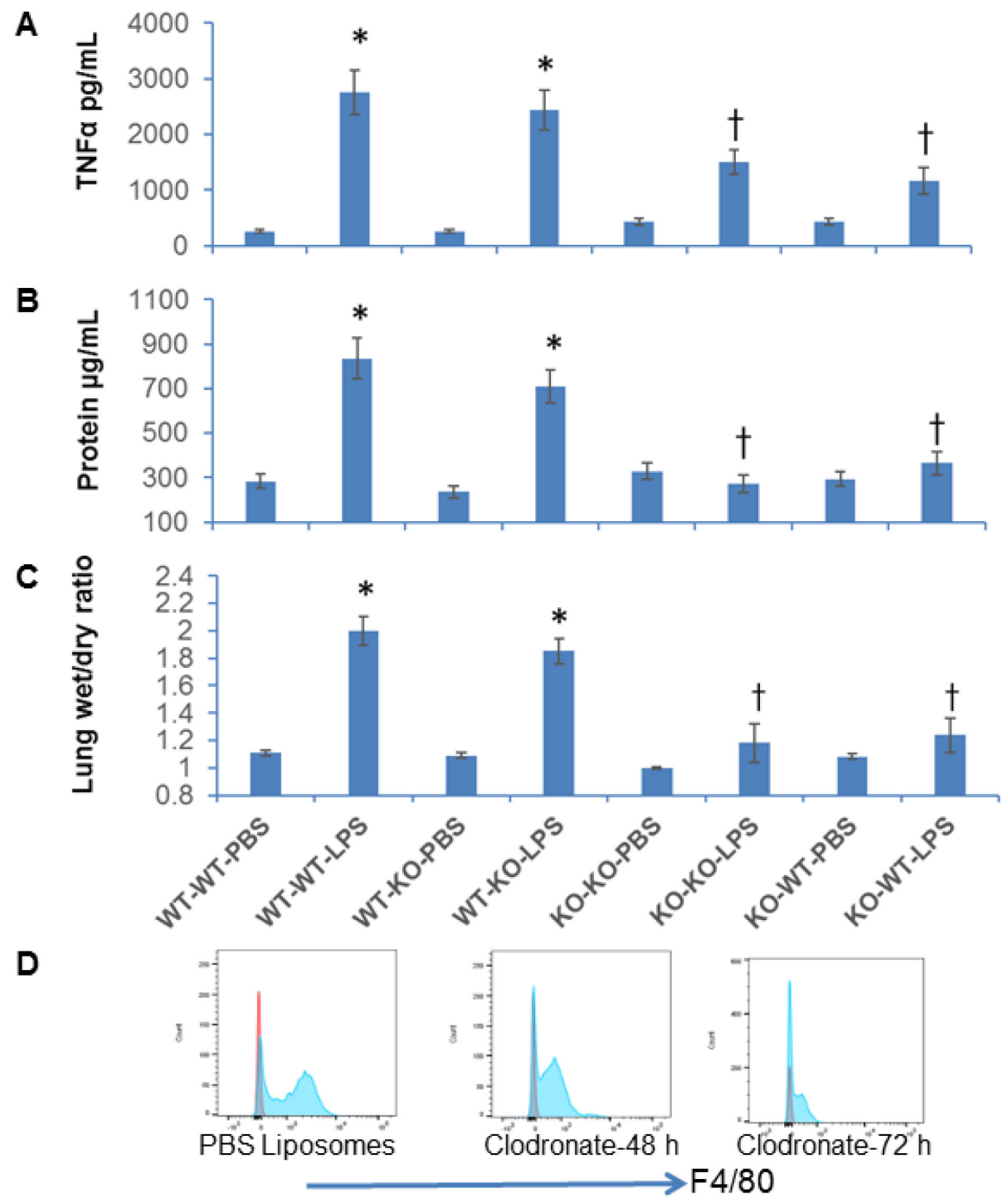

Figure 6: Adoptive transfer of $\mathrm{NFATc}^{-/}$macrophages protects mice against LPS induced acute lung injury. WT or $\mathrm{NFATc}^{-/-}$mice were pretreated with codronate liposomes for $72 \mathrm{~h}$ to deplete lung resident macrophages. The macrophage deleted mice were adoptively transferred with lung macrophages from reciprocal NFATc3 background and administered with i.p LPS (15 mg/kg). Pulmonary inflammation and edema was measured by (A) TNFa in BALF (B) BALF protein content (C) lung wet to dry ratios. (D) Depletion of lung resident macrophage population after clodronate liposome administration compared to PBS-liposomes was determined by flow sorting cells for CD45 and CD11b/F4/80 positive population. ${ }^{*} p \leq 0.01 \mathrm{WT}-\mathrm{WT}$ or WT-KO/LPS vs WT-WT or WT-KO/PBS; ${ }^{\dagger} p \leq$ $0.01 \mathrm{KO}-\mathrm{KO}-\mathrm{LPS}$ or KO-WT-LPS vs WT-WT-LPS or WT-KO-LPS. 
BMDMs (Figure 7C). CP9-ZIZIT clearly inhibited LPS induced nuclear translocation of NFATc3 as evidenced by immunofluorescence staining (Figure 8A, 8B). CP9-ZIZIT-Biotin/CP9-VAVAA-Biotin peptides were detected with anti-biotin-Streptavidin-PE and NFATc3 with antiNFATc3-antiRabbit-FITC (Figure 8A, 8B). More importantly, in vivo, CP9-ZIZIT pretreated mice $(1 \mathrm{mg} / \mathrm{kg}$ body weight, intranasal delivery) subjected to ALI by intranasal LPS instillation developed attenuated pulmonary edema and decreased cytokines (Figure 9A-9D). Similar to $\mathrm{NFATc}^{-/}$mice, CP9-ZIZIT pretreated mice showed decreased pulmonary edema, BALF cytokines and lung wet to dry ratios during sepsis-induced ALI. The uptake of CP9-ZIZIT-biotin/ CP9-VAVAA-biotin was around 45-50\% in lung macrophages (Figure 9E).

\section{DISCUSSION}

Innate immunity in response to pathogens relies on evolutionary conserved signaling pathways, involving the NF- $\kappa \mathrm{B}$ transcription factor. However, recent literature suggests that the nuclear factor of activated T-cell transcription factors, that share 'Rel homology' DNA binding domain similar to NF- $\kappa \mathrm{B}$ also contribute to innate immune response regulation. Exposure to microbial pathogens or inflammatory stimuli induces the activation of NFAT's in innate immune cells, including dendritic cells, granulocytes, macrophages and mast cells $[11,12$, $31,32]$. We reported earlier that activated NAFTc3 in macrophages regulates iNOS expression and thereby host microbial defense in murine abdominal sepsis models [6]. An immediate study by Zhang et al., (2014) implicated NFATc3 activation in regulating neutrophil recruitment, systemic inflammation and T-cell dysfunction during abdominal sepsis [33]. Current study using NFATC3 ${ }^{--}$ mice lead to an important finding that NFATc3 plays a pivotal role in the pathogenesis of sepsis induced ALI and pulmonary edema in murine models of sepsis.

From our findings, NFATc3 activation during sepsis conditions appears to be specific for macrophages and

A

B
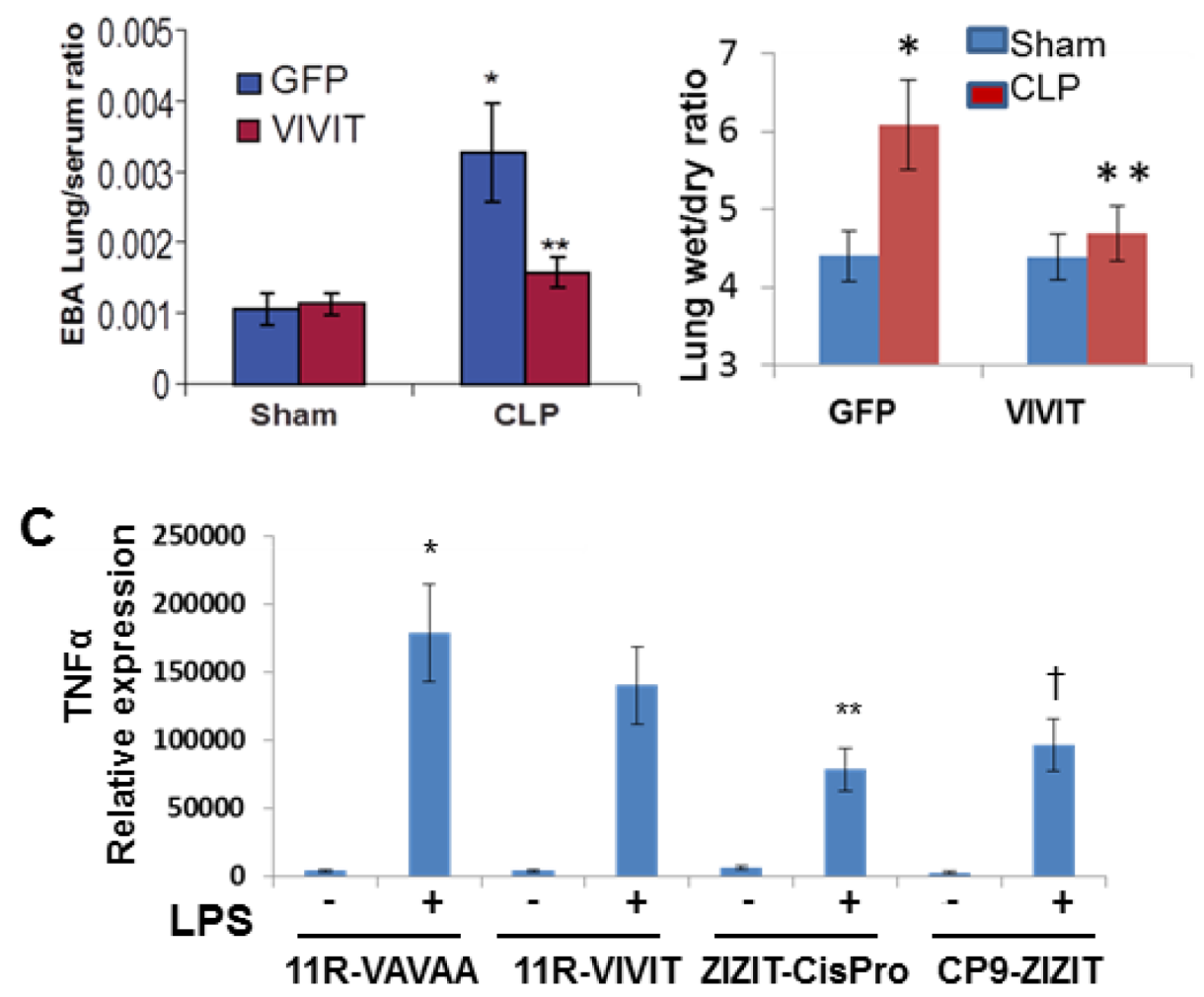

Figure 7: Pharmacological inhibition of NFAT attenuates pulmonary edema and inflammatory cytokines during sepsis-induced ALI. Wild type mice were administered with GFP-VIVIT or GFP plasmid containing liposomes $24 \mathrm{~h}$ before CLP or sham surgery. (A) 2\% Evans Blue Dye was injected retro-orbitally in to Sham and CLP mice and after 30 minutes mice were euthanized and lung vascular permeability was quantified by EBA extravasation. (B) Pulmonary edema was determined by differences in lung wet to dry weight ratios. In (A-B), ${ }^{*} p \leq 0.01$ CLP vs Sham; or GFP-VIVIT vs GFP. (C) BMDM were pretreated with $1 \mu$ M 11R-VAVAA, 11R-VIVIT, ZIZITcisPro or CP9-ZIZIT, separately and challenged with PBS/LPS for $8 \mathrm{~h}$. TNF $\alpha$ transcript levels were measured by reverse transcribing total Cdna and TNF $\alpha$ specific primers. ${ }^{*} p \leq 0.01$ LPS vs PBS; ${ }^{* *} p \leq 0.05$ ZIZITcisPro/LPS vs. $11 \mathrm{R}-\mathrm{VIVIT} / \mathrm{LPS}$. ${ }^{\dagger} p \leq 0.01 \mathrm{CP} 9$ ZIZIT/LPS vs 11R-VIVIT/LPS. 
was not observed in lung structural cells. Interestingly, NFATc3-deficient macrophages when stimulated with LPS showed attenuated expression of several cytokines, chemokines, and their receptors, thus translating to a profound phenotypic effect of NFATc3 deletion in sepsis induced ALI. NFATc3 deletion showed decreased pulmonary edema, neutrophilic inflammation, improved arterial oxygenation and survival during CLP-induced sepsis in mice. Binding of NFATc3 to CCR2, iNOS and TNF $\alpha$ promoters was increased during LPS treatment suggesting a regulatory role in ALI pathology. Interestingly, NFATc $3^{-/-}$mice showed increased bacterial infection in CLP mouse lungs due to decreased iNOS expression by macrophages, but significantly improved survival compared to WT mice when subjected to lethal CLP in presence of antibiotics. Although this could limit the clinical application of this approach, the combination of inhibiting the NFATc3 pathway and treatment with broad spectrum antibiotics seems to obviate this barrier and indicate that maintaining pulmonary barrier function is of paramount importance for survival and improved alveolar capillary gas exchange. Most importantly our data suggest that inhibition of NFATc3 and broad spectrum antibiotics could be used in combination in patients with severe sepsis. The mouse data has shown an impressive combined impact on survival that is not reported in earlier literature suggesting that blocking NFATc3 could be an effective adjunctive treatment for severe sepsis that would prevent the development of the acute respiratory distress syndrome (ARDS) and improve patient survival.

The cellular role of NFATc3-deficient macrophages in sepsis-induced ALI pathogenesis and pulmonary edema development is strongly supported by using novel high efficacy peptide inhibitors of NFATs in mouse lungs. GFPVIVIT expression plasmids significantly reduced sepsisinduced pulmonary edema in CLP mouse models. This part of our study has certain limitations as GFP-VIVIT is delivered to all the structural cells in lungs and it is not specific for NFATc3. However, as other members of NFAT (NFATc1, NFATc2 and NFATc4) are not activated in macrophages during LPS stimulation and NFATc3 is not activated in lung PMVEC and alveolar type II epithelial

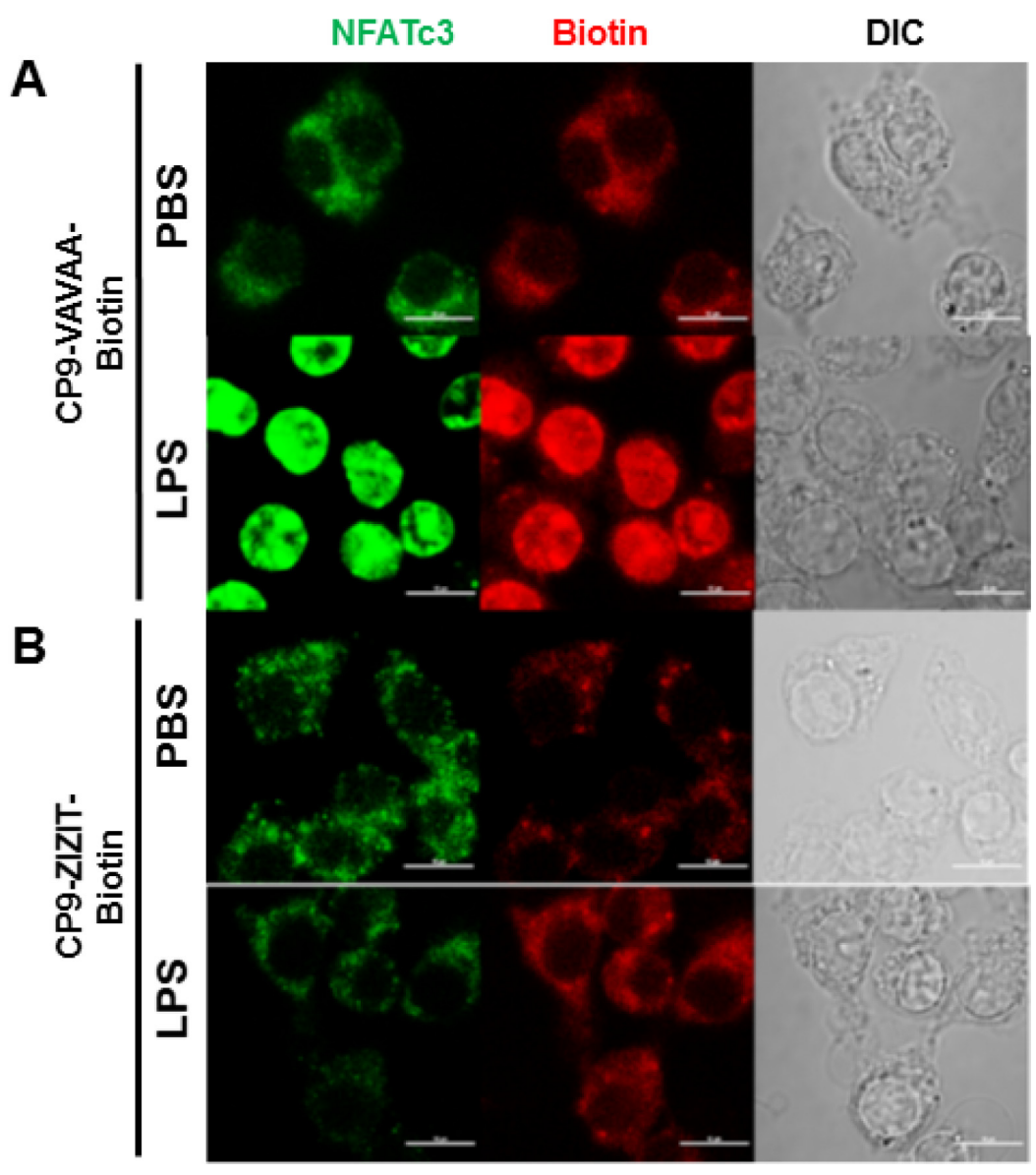

Figure 8: CP9-ZIZIT inhibits LPS induced NFATc3 nuclear translocation. Mouse BMDM were pretreated with $1 \mu \mathrm{M}$ of (A) control CP9-VAVAA or (B) CP9-ZIZIT inhibitor peptides and stimulated with PBS or LPS (100 ng/mL) for 1 hour. Localization of NFATc3 (green) and peptides (CP9-VAVAA or CP9-ZIZIT in red) with PBS/LPS stimulation is determined using Zeiss LSM 510 Meta microscope (Carl Zeiss MicroImaging, Inc.) equipped with $488 \mathrm{~nm}$ and $543 \mathrm{~nm}$ excitation lasers. Single confocal optical sections (pinhole set to achieve 1 Airy unit) are shown ( $n=7-10$ cells/group). Bars correspond to $10 \mu \mathrm{m}$. 
cells, the observed decrease in sepsis-induced pulmonary edema can be attributed to macrophage specific NFATc3 activation. This approach was further supported by using a novel potent NFAT blocker CP9-ZIZIT that significantly attenuated sepsis-induced ALI and pulmonary edema. Administering the CP9-ZIZIT directly into the lung would be expected to have less systemic toxicities and greater efficacy in preventing loss of alveolar capillary barrier function compared to using other available delivery methods. Other researchers have shown that inhibition of NFATs with the cell permeable 11R-VIVIT peptide has protective effect in an experimental colitis model in mice [31], improved immunosuppression during fully mismatched islet allografts between $\mathrm{BL} / 6$ and $\mathrm{C} 3 \mathrm{H} / \mathrm{HeN}$ mouse strains [34], and attenuated both microgliosis and Amyloid $\beta$ peptide $(A \beta)$ plaque load in mouse models of Alzheimer's disease [35]. Also, treatment with 11R-VIVIT markedly attenuates albuminuria in diabetic $\mathrm{db} / \mathrm{db}$ mice and alleviated mesangial matrix expansion and podocyte injury [36]. Furthermore, it was shown that blocking NFAT function was found to be beneficial in pulmonary arterial hypertension and acute pancreatitis [37, 38]. Role of NFAT members in different mouse disease models such as spontaneous pulmonary hypertension, diabetic
A
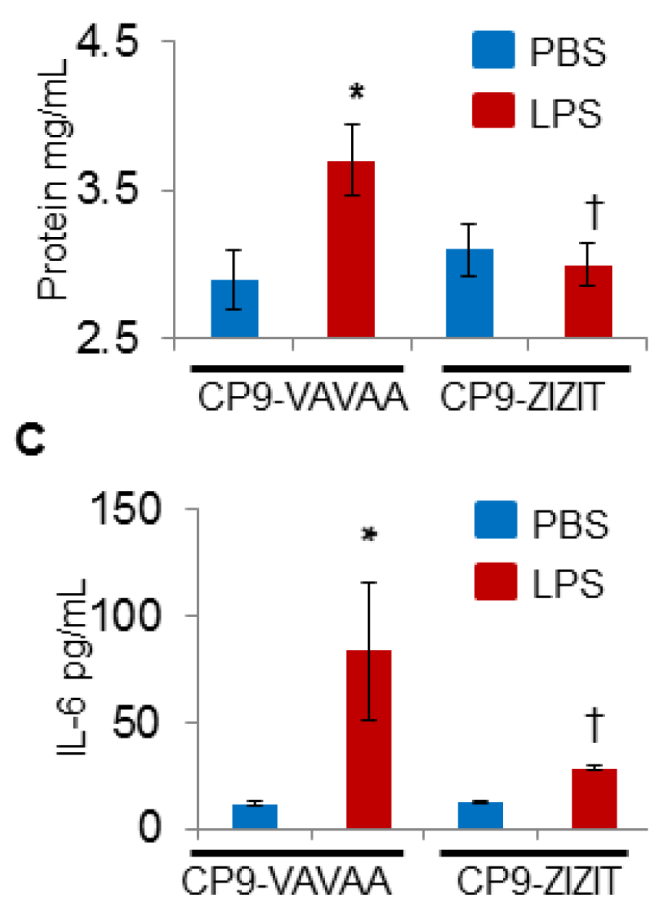

B
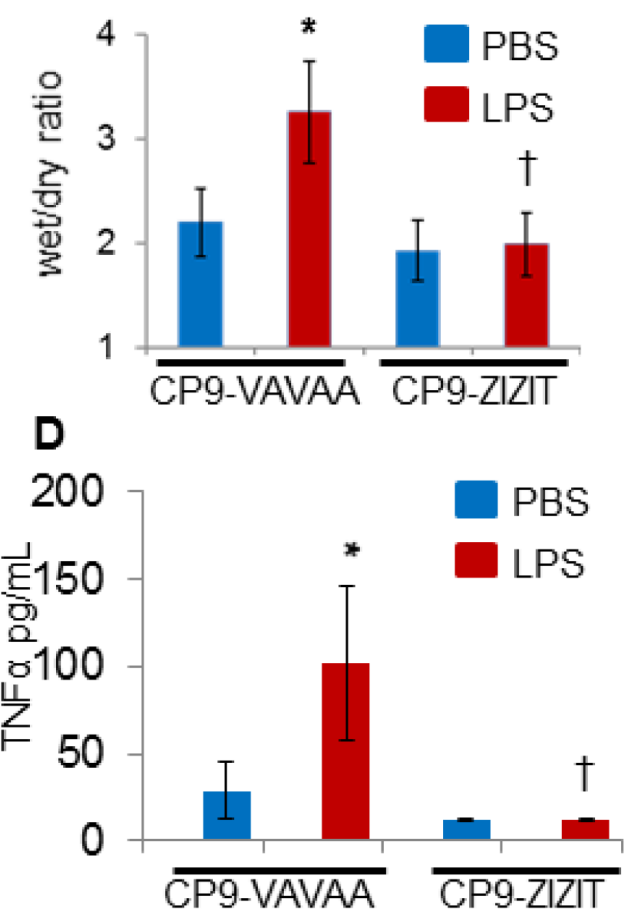

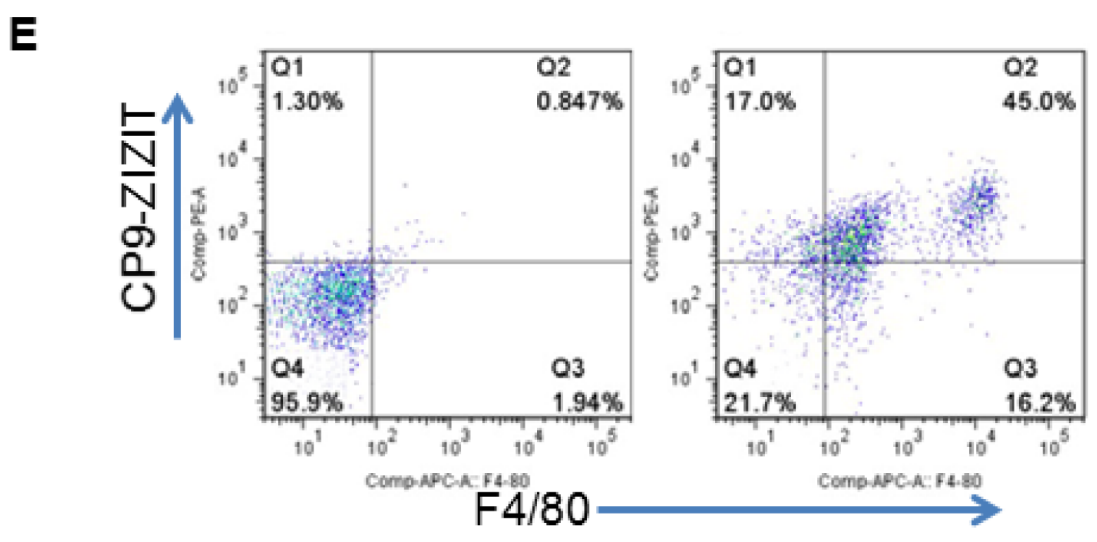

Figure 9: CP9-ZIZIT attenuates LPS induced pulmonary edema and cytokine storm in murine models of endotoxemia. WT mice were administered with CP9-ZIZIT or CP9-VAVAA at $1 \mathrm{mg} / \mathrm{kg}$ dose $1 \mathrm{~h}$ before nasal insufflation of LPS (10 $\mu \mathrm{g} / \mathrm{kg}$ ). (A-B) Pulmonary edema was measured by total BALF protein content and lung wet to dry ratios. (C-D) IL6 and TNF $\alpha$ release in to BALF during sepsis-induced ALI was determined using R\&D systems Quantikine IL6 and TNF $\alpha$ ELISA kits respectively. (E) Uptake of CP9-ZIZITBiotin by total lung macrophages is shown by flow cytometry. ${ }^{*} p \leq 0.01$ LPS vs PBS; ${ }^{\dagger} p \leq 0.01$ CP9-ZIZIT vs CP9-VAVAA. 
retinopathy is well documented $[39,40]$. In humans, liver allograft patients treated with Cyclosporine or Tacrolimus, showed increased NFAT dependent gene expression after 4-7 months or 8-12 months respectively [41]. In addition, the NFAT dependent gene expression was the maximum in all the subjects who rejected the transplant within one month indicating the critical role of NFAT's in inflammation and immunosuppression [41]. Recent studies also indicated NFAT dependent regulation of innate immune responses to fungal pathogens in rodents [42]. Thus, in addition to our data showing protection for ALI associated with severe sepsis, evidence that indicates the therapeutic potential of NFAT inhibition for a broad array of human maladies is accumulating.

Research efforts to identify NFAT inhibitors span over the last two decades but so far none of them performed well in the clinical trials [25, 26]. Interestingly, several alternative inhibitors including derivatives of cyclosporine like ISA247 were more potent and effectively inhibited Calcineurin, evaluated in phase III clinical trials against plaque psoriasis but did not result in to any commercial products so far $[43,44]$. Natural compounds like gossypol [45], kaempferol [46] and Arctigenin [47] and other plant based compounds also showed variable degree of NFAT inhibition [48-50]. The plant based inhibitors may have less toxic side effects compared to the widely used immuno-suppressants, Cyclosporine and Tacrolimus but are less potent in terms of activity. Peptide inhibitors of NFATs are relatively less explored, less toxic and hold good potential as drug candidates. The newly developed cell permeable calcineurin inhibitor CP9-ZIZIT showed promising activity in attenuating LPS induced ALI and pulmonary edema in mouse models. We are currently improving the properties of CP9-ZIZIT by structure based docking studies to further increase binding affinity, cellular uptake and proteolytic stability. In summary, our study supports the conclusion that NFATc3 has a pivotal role in mediating sepsis-induced ALI pathogenesis and pulmonary edema. Studies are underway to generate higher efficacy derivatives of CP9-ZIZIT and evaluate them in mouse post sepsis-ALI disease models.

\section{MATERIALS AND METHODS}

\section{Cells}

Bone marrow cells were differentiated into mature macrophages (BMDMs) from wild type C57BL/6 (WT) and $\mathrm{NFATc}^{-/-}$mice in DMEM supplemented with $10 \% \mathrm{FBS}, 1 \%$ penicillin/streptomycin and $20 \mathrm{ng} / \mathrm{mL}$ recombinant mouse M-CSF added on Day 1, 3 and 5. Cells were differentiated up to 7 days in total [4-6]. Mouse lung total macrophages were isolated by collagenase digestion, purified by adherence for 1 hour, plated in DMEM supplemented with 10\% FBS, 1\% penicillin/streptomycin [51]. Mouse PMVEC were isolated by Miltenyi CD31 magnetic beads. AEC type II cells were isolated as described earlier [52].
Mice

$\mathrm{NFATc}^{-/-}$in C57BL/6 background and wild type C57BL/6 mice were purchased from Jackson Laboratories and breeding colonies were maintained at the Ohio State University, Columbus. All the animal experiments and procedures were conducted with protocols approved by the Institutional Animal Care and Use Committee (IACUC) of OSU.

\section{Antibodies and fine chemicals}

Recombinant mouse M-CSF was purchased from PeproTech (Catalog\# 315-02, Rocky Hill, NJ). Antibodies for immunoblotting of proteins were purchased from different companies as indicated: NFATc3, NFATc2, NFATc1-Cell Signaling Technology (Catalog\# 4998, 4389, 8032, Danvers, MA), NFATc4-Santa Cruz (sc-13036, Dallas, TX), and $\alpha$-Tubulin-Santa Cruz (sc-8035). All the antibodies were validated in our earlier publications [6]. All primers and oligonucleotides were synthesized by IDT (Coralville, IA) and listed in supplement I. ChIP One Day Chromatin Immunoprecipitation kit was purchased from QIAGEN (Catalog\# 334471, Germantown, MD).

\section{Vectors and transfection reagents}

Myc-DDK tagged human NFATc3 expression vector (catalog\# RC212523) was purchased from Origene (Rockville, MD). Transient transfections were carried out using cell type-specific Lonza Electroporation kit using Amaxa Electroporator. GFP and GFP-VIVIT expression plasmids were obtained from Addgene (Cambridge, MA) and liposomes were prepared according to our published protocol $[2,4]$.

\section{Western blot analysis}

BMDMs or lung interstitial macrophages from WT or NFATc $3^{-/}$mice were harvested, and cell extracts were prepared in 1X RIPA buffer (Cell signaling Technologies catalog\# 9806) supplemented with protease inhibitors. An equal amount of protein was analyzed by Western blotting for the protein of interest using its specific antibodies according to standard protocols.

\section{Chromatin immunoprecipitation assay}

Binding of NFATc3 protein to NFATc3 consensus sequence in the TNF $\alpha$ promoter was assayed using QIAGEN Epitect Oneday Chromatin Immunoprecipitation kit as described earlier [53].

\section{Mouse pulmonary microvascular endothelial cell (PMVEC) monolayer permeability}

Millicell hanging cell culture inserts $(3.0 \mu \mathrm{m}$ pore size) were seeded with mouse PMVEC isolated by CD31 
Miltenyi magnetic micro beads up to $100 \%$ confluence and allowed to grow for 16 hours. NFATc $3^{--}$or WT BMDM grown in 24 well plates were stimulated with LPS for $8 \mathrm{hrs}$. The cell culture inserts containing PMVEC monolayer were transferred to 24 well plates containing LPS stimulated macrophages and co-cultured for an additional $24 \mathrm{hrs}$. FITC-Dextran (mol wt 10,000) was added to the upper compartment of the PMVEC monolayer inserts at the time of initiating the co-culture. Increased permeability of the EC monolayer was assessed by the flux of FITC-Dextran across the EC monolayers into the lower compartment of the wells by measuring fluorescence of the culture medium at $492 \mathrm{~nm}$ excitation and $523 \mathrm{~nm}$ emissions.

\section{Mouse models of sepsis}

Cecal ligation puncture (CLP) sepsis models were established according to Cuenca et al. [54]. In an anesthetized mouse, the cecum is exposed and ligated below ileo-cecal valve and two perforations were made across the cecum using $21 \mathrm{G}$ needle. The cecum is then compressed to express minute amount of fecal material. To establish moderate CLP sepsis the cecum was ligated at less than $1.0 \mathrm{~cm}$ from the distal end and for severe sepsis about $2.0 \mathrm{~cm}$ of the cecum from distal end was ligated. Pulmonary edema, arterial oxygenation, and inflammation were evaluated in moderate CLP sepsis models. Survival studies were carried out in the severely septic CLP mice. For the sham surgery group, the cecum was exposed and repositioned back in the abdominal cavity before suturing the skin layers separately. LPS $(15 \mathrm{mg} / \mathrm{kg})$ or the same volume of normal saline was administered into intraperitoneal cavity of WT or NFATc $3^{-/}$mice and arterial oxygenation was measured by pulse oximetry.

\section{Pulmonary arterial oxygenation by pulse oximetry}

Following LPS injection, the fur around the neck of each mouse was shaved and pulmonary arterial oxygenation status of each mouse was measured at 8 and 24 hours by MouseOx Plus (Starr Life Sciences Corp, USA) in accordance with manufacturer's instructions. Each mouse was allowed to acclimatize for 1 hour after placement of a collar clip sensor. Oxygen saturation measurements were recorded for 5 minutes for 5 times and then averaged.

\section{Pulmonary neutrophilic inflammation and edema}

WT and NFATc $3^{-1-}$ mice were subjected to moderate CLP and after $24 \mathrm{~h}$ post sepsis, cytospin slides were prepared from broncho alveolar lavage fluid (BALF). Cytospin slides were stained using Hema 3.0 and neutrophils and macrophages were counted and differences were compared for statistical significance. The protein content in cell-free BALF was determined as described earlier [4].

\section{Lung capillary leakage and wet/dry ratio measurement}

Evans Blue-labeled albumin (EBA) was administered intravenously in Sham/PBS and CLP/LPS group of mice. After 30 minutes post EBA injection, the mice were euthanized to assess vascular leakage in the right lobes. Additionally, the left lobe of the lung was excised, weighed, and dried in the oven at $60^{\circ} \mathrm{C}$ for 18 hours. EBA extravasation and the difference between the lung wet/dry ratios were quantitated in sham and CLP mice as described earlier [4].

\section{Kaplan meier survival curves}

$\mathrm{NFATc}^{-/-}$and WT mice were subjected to severe sepsis by CLP and observed for number of deaths over a period of 96 h. Kaplan Meier survival curves of different mice groups was plotted using OriginProâ statistical software [55].

\section{Adoptive transfer of Macrophages}

Mouse lung resident macrophages from recipient mice $(n=5)$ were depleted by nasal insufflation of $50 \mu \mathrm{L}$ of clodrosome or control liposomes (Encapsula LLC). After $72 \mathrm{~h}$ of clodrosome delivery, $1 \times 10^{6}$ lung macrophages (isolated by collagenase/DNase digestion, adherence purified) from donor mice are delivered in to trachea of the recipient mice. Mice transferred with WT to

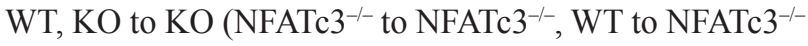
or NFATc $3^{--}$to WT macrophages are subjected to LPS or PBS (i.p) challenge. BALF protein, cytokines and lung wet/dry ratio were determined in the recipient mice subjected to LPS/PBS treatments.

\section{Statistical analysis}

All the experiments were repeated three to four times to test for consistency and representative data sets are presented for EMSA, WB and flow cytometry. For all the data sets involving in vitro cell assays and mouse CLP/ LPS sepsis models, statistical analyses were performed using non-paired Student's $t$ test or ANOVA and $p \leq$ 0.05 was considered significant. Error bars represent standard deviation/standard error. Statistical significance is indicated in corresponding figure legends.

\section{Author contributions}

J.W.C. M.K. Conceived and designed the experiments. Z.Q. J.W. D.P. CP9-ZIZIT synthesis and support. M.K. S.W.C. Y.G.L. L.R. T.S.N. Performed experiments. M.K. J.D B.F.R M.N.B Performed mouse experiments. J.W.C. M.K. Analyzed the data and wrote paper. 


\section{CONFLICTS OF INTEREST}

The authors declare no competing financial interests.

\section{FUNDING}

This study was supported by the National Institutes of Health (JWC -R01 HL075557, HL 103643, and T32 HL082547) and American Heart Association (MK AHA17SDG33410982).

\section{REFERENCES}

1. Elder A, Johnston C, Gelein R, Finkelstein J, Wang Z, Notter R, Oberdörster G. Lung inflammation induced by endotoxin is enhanced in rats depleted of alveolar macrophages with aerosolized clodronate. Exp Lung Res. 2005; 31:527-546.

2. Koay MA, Gao X, Washington MK, Parman KS, Sadikot RT, Blackwell TS, Christman JW. Macrophages are necessary for maximal nuclear factor-kappa B activation in response to endotoxin. Am J Respir Cell Mol Biol. 2002; 26:572-578.

3. Maus UA, Koay MA, Delbeck T, Mack M, Ermert M, Ermert L, Blackwell TS, Christman JW, Schlöndorff D, Seeger W, Lohmeyer J. Role of resident alveolar macrophages in leukocyte traffic into the alveolar air space of intact mice. Am J Physiol Lung Cell Mol Physiol. 2002; 282:L1245-1252.

4. Karpurapu M, Wang X, Deng J, Park H, Xiao L, Sadikot RT, Frey RS, Maus UA, Park GY, Scott EW, Christman JW. Functional PU.1 in macrophages has a pivotal role in $\mathrm{NF}-\kappa \mathrm{B}$ activation and neutrophilic lung inflammation during endotoxemia. Blood. 2011; 118:5255-5266.

5. Deng J, Wang X, Qian F, Vogel S, Xiao L, Ranjan R, Park H, Karpurapu M, Ye RD, Park GY, Christman JW. Protective role of reactive oxygen species in endotoxininduced lung inflammation through modulation of IL-10 expression. J Immunol. 2012; 188:5734-5740.

6. Ranjan R, Deng J, Chung S, Lee YG, Park GY, Xiao L, Joo M, Christman JW, Karpurapu M. The transcription factor nuclear factor of activated $\mathrm{T}$ cells $\mathrm{c} 3$ modulates the function of macrophages in sepsis. J Innate Immun. 2014; 6:754-764.

7. Mancini M, Toker A. NFAT proteins: emerging roles in cancer progression. Nat Rev Cancer. 2009; 9:810-20.

8. Macian F. NFAT proteins: key regulators of T-cell development and function. Nat Rev Immunol. 2005; 5:472-84.

9. Jain J, McCaffrey PG, Miner Z, Kerppola TK, Lambert JN, Verdine GL, Curran T, Rao A. The T-cell transcription factor NFATp is a substrate for calcineurin and interacts with Fos and Jun. Nature. 1993; 365:352-355.

10. Chow CW, Rincón M, Davis RJ. Requirement for transcription factor NFAT in interleukin-2 expression. Mol Cell Biol. 1999; 19:2300-2307.
11. Zanoni I, Ostuni R, Capuano G, Collini M, Caccia M, Ronchi AE, Rocchetti M, Mingozzi F, Foti M, Chirico G, Costa B, Zaza A, Ricciardi-Castagnoli P, et al. CD14 regulates the dendritic cell life cycle after LPS exposure through NFAT activation. Nature. 2009; 460:264-268.

12. Feske $\mathrm{S}$, Okamura H, Hogan PG, Rao A. Ca2+/calcineurin signalling in cells of the immune system. Biochem Biophys Res Commun. 2003; 311:1117-1132.

13. Sitara D, Aliprantis AO. Transcriptional regulation of bone and joint remodeling by NFAT. Immunol Rev. 2010; 233:286-300.

14. Savage SR, Bretz CA, Penn JS. RNA-Seq reveals a role for NFAT-signaling in human retinal microvascular endothelial cells treated with TNF $\alpha$. PLoS One. 2015; 10:e0116941.

15. Wei J, Du K, Cai Q, Ma L, Jiao Z, Tan J, Xu Z, Li J, Luo W, Chen J, Gao J, Zhang D, Huang C. Lead induces COX-2 expression in glial cells in a NFAT-dependent, AP-1/NFKBindependent manner. Toxicology. 2014; 325:67-73.

16. Zhou X, Zhang Q, Zhao T, Bai X, Yuan W, Wu Y, Liu D, Li S, Ju J, Chege Gitau S, Chu W, Xu C, Lu Y. Cisapride protects against cardiac hypertrophy via inhibiting the up-regulation of calcineurin and NFATc-3. Eur J Pharmacol. 2014; 735:202-210.

17. Shiratori M, Tozaki-Saitoh H, Yoshitake M, Tsuda M, Inoue $\mathrm{K} . \mathrm{P} 2 \mathrm{X} 7$ receptor activation induces CXCL2 production in microglia through NFAT and PKC/MAPK pathways. J Neurochem. 2010; 114:810-819.

18. Furman JL, Sompol P, Kraner SD, Pleiss MM, Putman EJ, Dunkerson J, Mohmmad Abdul H, Roberts KN, Scheff SW, Norris CM. Blockade of Astrocytic Calcineurin/NFAT Signaling Helps to Normalize Hippocampal Synaptic Function and Plasticity in a Rat Model of Traumatic Brain Injury. J Neurosci. 2016; 36:1502-1515.

19. Graef IA, Chen F, Crabtree GR. NFAT signaling in vertebrate development. Curr Opin Genet Dev. 2001; 11:505-512.

20. Schulz RA, Yutzey KE. Calcineurin signaling and NFAT activation in cardiovascular and skeletal muscle development. Dev Biol. 2004; 266:1-16.

21. Zaslavsky A, Chou ST, Schadler K, Lieberman A, Pimkin M, Kim YJ, Baek KH, Aird WC, Weiss MJ, Ryeom S. The calcineurin-NFAT pathway negatively regulates megakaryopoiesis. Blood. 2013; 121:3205-3215.

22. Serrano-Pérez MC, Fernández M, Neria F, Berjón-Otero M, Doncel-Pérez E, Cano E, Tranque P. NFAT transcription factors regulate survival, proliferation, migration, and differentiation of neural precursor cells. Glia. 2015; 63:987-1004.

23. Miyakawa H, Woo SK, Dahl SC, Handler JS, Kwon HM. Tonicity-responsive enhancer binding protein, a rel-like protein that stimulates transcription in response to hypertonicity. Proc Natl Acad Sci U S A. 1999; 96:2538-2542.

24. Hogan PG, Chen L, Nardone J, Rao A. Transcriptional regulation by calcium, calcineurin, and NFAT. Genes Dev. 2003; 17:2205-32. 
25. Sieber M, Baumgrass R. Novel inhibitors of the calcineurin/ NFATc hub - alternatives to CsA and FK506? Cell Commun Signal. 2009; 7:25.

26. Erdmann F, Weiwad M. Calcineurin inhibitors: status quo and perspectives. Biomol Concepts. 2011; 2:65-78.

27. Aramburu J, Yaffe MB, López-Rodríguez C, Cantley LC, Hogan PG, Rao A. Affinity-driven peptide selection of an NFAT inhibitor more selective than cyclosporin A. Science. 1999; 285:2129-2133.

28. Qian Z, Dougherty PG, Liu T, Oottikkal S, Hogan PG, Hadad CM, Pei D. Structure-based optimization of a peptidyl inhibitor against calcineurin-nuclear factor of activated T cell (NFAT) interaction. J Med Chem. 2014; 57:7792-7797.

29. Qian Z, Liu T, Liu YY, Briesewitz R, Barrios AM, Jhiang SM, Pei D. Efficient delivery of cyclic peptides into mammalian cells with short sequence motifs. ACS Chem Biol. 2013; 8:423-31.

30. Qian Z, Martyna A, Hard RL, Wang J, Appiah-Kubi G, Coss C, Phelps MA, Rossman JS, Pei D. Discovery and mechanism of highly efficient cyclic cell-penetrating peptides. Biochemistry. 2016; 55:2601-2612.

31. Elloumi HZ, Maharshak N, Rao KN, Kobayashi T, Ryu HS, Mühlbauer M, Li F, Jobin C, Plevy SE. A cell permeable peptide inhibitor of NFAT inhibits macrophage cytokine expression and ameliorates experimental colitis. PLoS One. 2012; 7:e34172.

32. Klein M, Klein-Hessling S, Palmetshofer A, Serfling E, Tertilt C, Bopp T, Heib V, Becker M, Taube C, Schild H, Schmitt E, Stassen M. Specific and redundant roles for NFAT transcription factors in the expression of mast cellderived cytokines. J Immunol. 2006; 177:6667-6674.

33. Zhang S, Luo L, Wang Y, Gomez MF, Thorlacius H. Nuclear factor of activated $\mathrm{T}$ cells regulates neutrophil recruitment, systemic inflammation, and T-cell dysfunction in abdominal sepsis. Infect Immun. 2014; 82:3275-88.

34. Noguchi H, Matsushita M, Okitsu T, Moriwaki A, Tomizawa K, Kang S, Li ST, Kobayashi N, Matsumoto S, Tanaka K, Tanaka N, Matsui H. A new cell-permeable peptide allows successful allogeneic islet transplantation in mice. Nat Med. 2004; 10:305-309.

35. Rojanathammanee L, Floden AM, Manocha GD, Combs CK. Attenuation of microglial activation in a mouse model of Alzheimer's disease via NFAT inhibition. J Neuroinflammation. 2015; 12:42.

36. Zhang L, Li R, Shi W, Liang X, Liu S, Ye Z, Yu C, Chen Y, Zhang B, Wang W, Lai Y, Ma J, Li Z, Tan X. NFAT2 inhibitor ameliorates diabetic nephropathy and podocyte injury in db/db mice. Br J Pharmacol. 2013; 170:426-439.

37. Bonnet S, Rochefort G, Sutendra G, Archer SL, Haromy A, Webster L, Hashimoto K, Bonnet SN, Michelakis ED. The nuclear factor of activated $\mathrm{T}$ cells in pulmonary arterial hypertension can be therapeutically targeted. Proc Natl Acad Sci USA. 2007; 104:11418-23.

38. Awla D, Zetterqvist AV, Abdulla A, Camello C, Berglund LM, Spégel P, Pozo MJ, Camello PJ, Regnér S, Gomez MF, Thorlacius H. NFATc3 regulates trypsinogen activation, neutrophil recruitment, and tissue damage in acute pancreatitis in mice. Gastroenterology. 2012; 143:1352-1360.

39. Ramiro-Diaz JM, Nitta CH, Maston LD, Codianni S, Giermakowska W, Resta TC, Gonzalez Bosc LV. NFAT is required for spontaneous pulmonary hypertension in superoxide dismutase 1 knockout mice. Am J Physiol Lung Cell Mol Physiol. 2013; 304:L613-25.

40. Zetterqvist AV, Blanco F, Öhman J, Kotova O, Berglund LM, de Frutos Garcia S, Al-Naemi R, Wigren M, McGuire PG, Gonzalez Bosc LV, Gomez MF. Nuclear factor of activated $\mathrm{T}$ cells is activated in the endothelium of retinal microvessels in diabetic mice. J Diabetes Res. 2015; 2015:428473.

41. Steinebrunner N, Sandig C, Sommerer C, Hinz U, Giese T, Stremmel W, Zahn A. Pharmacodynamic monitoring of nuclear factor of activated $\mathrm{T}$ cell-regulated gene expression in liver allograft recipients on immunosuppressive therapy with calcineurin inhibitors in the course of time and correlation with acute rejection episodes - a prospective study. Ann Transplant. 2014; 19:32-40.

42. Herbst S, Shah A, Mazon Moya M, Marzola V, Jensen B, Reed A, Birrell MA, Saijo S, Mostowy S, Shaunak S, Armstrong-James D. Phagocytosis-dependent activation of a TLR9-BTK-calcineurin-NFAT pathway co-ordinates innate immunity to Aspergillus fumigatus. EMBO Mol Med. 2015; 7:240-258.

43. Birsan T, Dambrin C, Freitag DG, Yatscoff RW, Morris RE. The novel calcineurin inhibitor ISA247: a more potent immunosuppressant than cyclosporine in vitro. Transpl Int. 2005; 17:767-771.

44. Papp K, Bissonnette R, Rosoph L, Wasel N, Lynde CW, Searles G, Shear NH, Huizinga RB, Maksymowych WP. Efficacy of ISA247 in plaque psoriasis: a randomised, multicentre, double-blind, placebo-controlled phase III study. Lancet. 2008; 371:1337-1342.

45. Carruthers NJ, Dowd MK, Stemmer PM. Gossypol inhibits calcineurin phosphatase activity at multiple sites. Eur J Pharmacol. 2007; 555:106-114.

46. Wang H, Zhou CL, Lei H, Zhang SD, Zheng J, Wei Q. Kaempferol: a new immunosuppressant of calcineurin. IUBMB Life. 2008; 60:549-554.

47. Yamashita T, Uehara S, Udagawa N, Li F, Kadota S, Esumi H, Kobayashi Y, Takahashi N. Arctigenin inhibits osteoclast differentiation and function by suppressing both calcineurin-dependent and osteoblastic cell-dependent NFATc1 pathways. PLoS One. 2014; 9:e85878.

48. Kiem PV, Minh CV, Huong HT, Lee JJ, Lee IS, Kim YH. Phenolic constituents with inhibitory activity against NFAT 
transcription from Desmos chinensis. Arch Pharm Res. 2005; 28:1345-1349.

49. Lee SI, Kim BS, Kim KS, Lee S, Shin KS, Lim JS. Immune-suppressive activity of punicalagin via inhibition of NFAT activation. Biochem Biophys Res Commun. 2008; 371:799-803.

50. Márquez N, Sancho R, Macho A, Calzado MA, Fiebich BL, Muñoz E. Caffeic acid phenethyl ester inhibits T-cell activation by targeting both nuclear factor of activated T-cells and NF-kappaB transcription factors. J Pharmacol Exp Ther. 2004; 308:993-1001.

51. Ballinger MN, Paine R 3rd, Serezani CH, Aronoff DM, Choi ES, Standiford TJ, Toews GB, Moore BB. Role of granulocyte macrophage colony-stimulating factor during gram-negative lung infection with Pseudomonas aeruginosa. Am J Respir Cell Mol Biol. 2006; 34:766-774.
52. Corti M, Brody AR, Harrison JH. Isolation and primary culture of murine alveolar type II cells. Am J Respir Cell Mole Biol. 1996; 14:309-315.

53. Karpurapu M, Ranjan R, Deng J, Chung S, Lee YG, Xiao L, Nirujogi TS, Jacobson JR, Park GY, Christman JW. Krüppel like factor 4 promoter undergoes active demethylation during monocyte/macrophage differentiation. PLoS One. 2014; 9:e93362.

54. Cuenca AG, Delano MJ, Kelly-Scumpia KM, Moldawer LL, Efron PA. Cecal ligation and puncture. Curr Protoc Immunol. 2010; Chapter 19: Unit 19.13.

55. Seifer TE. OriginPro 9.1: scientific data analysis and graphing software-software review. J Chem Inf Model. 2014; 54:1552. 